\title{
The Effect of an Educational Intervention with Spouse's Participation on Food Intake of Pregnant Females: A Randomized Controlled Trial
}

\author{
Azita Kiani Asiabar ${ }^{1}$, Farkhondeh Amin Shokravi (iD) ${ }^{2,}{ }^{*}$, Majid Hajifaraji ${ }^{3}$ and Farid Zayeri ${ }^{4}$ \\ ${ }^{1}$ Department of Health Education and Health Promotion, Faculty of Medical Sciences, Tarbiat Modares University, Tehran, IR Iran \\ ${ }^{2}$ Health Education and Health Promotion Department, Faculty of Medical Sciences, Tarbiat Modares University, Tehran, IR Iran \\ ${ }^{3}$ National Nutrition and Food Technology Research Institute, School of Nutrition Sciences and Food Technology, Shahid Beheshti University of Medical Sciences, Tehran, IR \\ Iran \\ ${ }^{4}$ Department of Biostatistics, Faculty of Paramedical Sciences, Shahid Beheshti University of Medical Sciences, Tehran, IR Iran \\ "Corresponding author: PhD, Department of Health Education and Health Promotion, Faculty of Medical Sciences, Tarbiat Modares University, No. 7, Jalal Al Ahmad Street, \\ Tehran 14115-116, IR Iran. Tel: +98-2182884506, Fax: +98-2182884555, E-mail: aminsh_f@modares.ac.ir
}

Received 2017 June 21; Revised 2017 September 17; Accepted 2017 October 21.

\begin{abstract}
Background: Spouses can influence their wife's health during pregnancy. However, dietary intake comprised of high value nutrition in addition to spouses' participation during pregnancy is an important aspect of female's health, which has been widely neglected.

Objectives: This study aimed at evaluating the effectiveness of educational programs with spouse's participation on dietary during pregnancy.

Methods: In the randomized controlled trial study, 128 nulliparous females attending Najmieh hospital based in Tehran, Iran, were randomly allocated to 2 intervention and 1 control group. In Group A, females received nutritional education with their spouses' participation, in Group B, females received nutritional education alone, and in Group C, females received routine prenatal care, yet no guidance on dietary intake. Data was collected by completing 2 questionnaires, including demographic characteristics and the semi-quantitative food frequency questionnaire (FFQs).

Results: In this trial study, the mean differences of serving/day of vegetables and yogurt from the dairy range was significantly higher in group A compared to B and the control group (1.27 serving/day vegetables - group A compared to 0.81 and 0.41 serving/day vegetables in groups $\mathrm{B}$ and $\mathrm{C}$, respectively; $\mathrm{P}<0.001$, and 0.56 serving/day of yogurt in group A versus 0.33 and 0.32 serving/day of yogurt in groups B and C, respectively, $\mathrm{P}<0.024$ ). The mean differences of serving/day of dairy in groups A and B were significantly higher than the control group ( 1.97 and 1.66 serving/day in groups $A$ and $B$, respectively versus 0.81 serving/day in the group $C, P=$ 0.003). In addition, the mean differences of serving/day for fat sources in the intervention groups were significantly lower than the control group (2.58 and 1.18 serving/day in groups A and B, respectively versus 0.38 serving/day in the group $\mathrm{C}, \mathrm{P}=0.035$ ).

Conclusions: The findings found improvement in intervention group A with intake of vegetables and yoghurt as dairy sources compared to Group B. In addition, their mean differences of dairy source was higher than Group C, while serving of fat sources was lower in both groups compared to the control group.
\end{abstract}

Keywords: Dietary Intake, Intervention Groups, Pregnancy, Spouses' Participation

\section{Background}

Enhancing quality of maternal diet during pregnancy is an essential factor $(1,2)$ and spouses' participation is poised to be an important facilitator of this process (3-6).

Studies have shown that a lack of nourishment could lead to a range of health problems, such as overweightness/obesity, preeclampsia, hypertension, and gestational diabetes during pregnancy (7-9). Poor nutrition is a significant risk factor for inappropriate gestational weight gain and all its attendant adverse consequences $(10,11)$. Maternal diet must provide sufficient energy and proper nutri- ents during pregnancy, focusing on the growing fetus and enabling the mother to reserve her nutrients supply required for fetal health as well as for breastfeeding practices $(12,13)$.

According to previous studies, although pregnant females based in Iran are often well weighed, their food intake patterns are inappropriate and their diet lacks proteins, vitamins, and in general, micronutrients (14-16), which include Calcium, Iron, Zinc, Vitamin A and D (17-20).

Therefore, it is important to gain a better understanding of dietary patterns during pregnancy. 
In addition, male's participation as a decision maker in the family and society has often received less attention in implementation of strategies for reducing maternal morbidity and mortality (21); commonly observed in developing countries $(12,22)$.

Indirect evidence from several studies has shown that spouses' role in prenatal care has ensured better pregnancy outcomes and maternal health (23-25). Educational programs for spouse's participation in maternal health care should aim at increasing their awareness of obstetric emergencies and involving them in child birth and its complications (13).

Spouses' participation enables them to support their wives in prenatal cares wherein building awareness among couples to adequately prepare for birth complications (26). However, when it comes to prenatal care by the husband, 2 phases of delay are commonly involved, such as delay in decision making process and delay in providing and receiving prenatal care, mainly observed in developing countries (27).

In addition, Iranian males are usually the source of financial support in the family and thus have an important role in sourcing food supply. Various studies have emphasized on multi-dimensional intervention strategies as a need to improve nutritional status of pregnant females $(28,29)$. Education on the signs of risks and suitable nutrition is necessary to make proper and timely decisions, which lead to a marked decrease in the morbidity and mortality of both the mother and the infant (30). However, decisions about spending on food intake is predominantly male-oriented, as males are the sole breadwinner.

This paper presents results of an interventional study through innovative approaches, including male-focused interventions, in which the effect of husband's involvement in prenatal health on promotion of food intake was assessed.

\section{Methods}

\subsection{Design}

This study was conducted by a single-blind randomized controlled trial with 3 parallel arms to evaluate the effectiveness of an educational program with spouses' participation, regarding improvement of pregnant female's diet during their first pregnancy. The samples were selected from those, who had referred to a single health care center over a 6-month period, during year 2016. Simple randomization was used along with the NCSS 11.0 software.

\subsection{Participants}

In this study, subjects were nulliparous pregnant females, who had referred to a single hospital center (a general and governmental hospital) located in Tehran, Iran.
The inclusion criteria were being a nulliparous female in the 10th to 12th week of pregnancy (based on the first day of the last menstrual cycle-LMP or ultrasound result), single pregnancy, wanted pregnancy, lack of chronic diseases and any disease, which needs a particular nutritional pattern before and during pregnancy, not having a vegan diet, not having a special diet, living permanently with one's spouse, and signing the written consent form.

The Exclusion criterion was having had miscarriage or abortion during pregnancy. Overall, 150 nulliparous females were randomly assigned to 3 groups ( 50 subjects in each group), including groups A, B, and C. On submission of written consent form, group A received nutritional education with their spouses, Group B only received nutritional education, and group $C$ only received routine prenatal care, but no advice on dietary intake.

The intervention was performed by a research scholar (PhD candidate), who was a trained midwife. After providing a written consent, data from each group was collected at 2 intervals, before the intervention $(\sim 10$ th to 12 th week of pregnancy) and 4 weeks after the intervention ( 14 th to 16th week of pregnancy). In addition, in the first visit, address and contact details were collected from the participants for further follow ups.

\subsection{Intervention}

Prior to the research trial and based on the pre-test data and relevant literature, a booklet was developed on the basis of comprehensive guide for nutrition during pregnancy and breastfeeding by the ministry of health and medical education (MOHME) of Iran (31).

According to this booklet, focus on the essential dietary component was explained, including general topics, such as energy balance and a healthy nutrition. In addition, participants were informed about added energy requirements from a variety of foods as well as macro- and micro nutrient requirements during pregnancy. The dietary intervention emphasized on decreasing the intake of energy-dense foods and high-fat foods (e.g. fast foods and sugar-sweetened beverages/ products) by replacing them with low fat and or sugar substitutes and increasing the duration and the amount of fruits, vegetables, and dairy products. Another target was to improve the quality of fat sources consumed by increasing the amount white meat consumption, which is a leaner source of protein, with a lower fat content, such as fish and chicken, compared to red meat in the diet, and choosing essential fats/oil for cooking and/or use as spreads.

In addition, they were recommended to choose a proper range of servings based on Ministry of Health and Medical Education (MOHME), Iran. For example, the current Iranian national dietary guideline recommends 3 servings of dairy products, 2 to 4 servings of fruits and 3 
to 5 servings of vegetables, daily during pregnancy. As individual cases, dietary records were analyzed by checking for peculiar dietary characteristics.

This booklet was distributed among pregnant females in the intervention groups ( $\mathrm{A}$ and $\mathrm{B}$ ), and nutrition educational counselling was held during two 90-minute intervals added to the routine prenatal care. Furthermore, during the sessions, time was allocated for discussions and questions. The intervention involved 2 methods of oral (counselling) and written material (the booklet), given during the 10th to 12th and 11th to 13th week of gestation, with a gap of 1 week.

The counselling sessions were structured focusing mainly on nulliparous female's nutritional dietary intake. The first session lasted up to 90 minutes and second counselling session (90 minutes) reviewed the topics, which were mentioned in the first session yet in more depth and addressed selected aspects in a problem-oriented manner. The control group received routine prenatal care only.

During the study, the educational material on nutritional dietary intake were sent to the subjects via social messaging services "Telegram/ Line" as all the participants had access to related applications. Telegram/Line education package included of 3 to 5 informative short messages as texts and figures about the kind of foods, the importance of dairy intake, vegetables, benefits of lipid reduction, especially saturated fats on the health of the mother and developing fetus, and sufficiency of food supply during pregnancy. The service network frequently monitored whether the participants read the messages. Electronic learning continued during the 4 weeks addressing questions during the session. All participants were contacted and asked to complete the post-test questionnaire at the hospital 4 weeks after the last educational session and all the pregnant females completed the questionnaire.

\subsection{Data Collection}

Mothers' dietary intakes were assessed during pregnancy, using a 147-item semi-quantitative food frequency questionnaire (FFQs). The FFQs consisted of a list of foods with standard serving sizes, and was validated by a lipid and glucose study and used to assess dietary intake of Iranian adults based in Tehran (32). Participants were asked to report their usual consumed frequency of a given serving of each food item during the first trimester of pregnancy (10 to 12 weeks) at baseline and 4 weeks after the last counselling session on a daily, weekly, and monthly basis. All reported consumption frequencies for each food item was then converted to a daily intake.

The food groups were assessed by face-to-face personal interviews conducted by a trained research scholar, and the data were collected from the participants, omitting any missing data.
To identify the food groups, considering the latest food classifications in Iran (33), food items were firstly aggregated from the FFQs; the food groups included processed meats, meat and eggs, milk and dairy, fruits and natural fruit juices, vegetables, bread and grains, fats, legumes and pulses, nuts and seeds, and sweets and dessert enlisted into 10 food groups (Table 1). The serving size per day was calculated using the United States department of agriculture guidelines (USDA) (34).

The mother's Body Mass Index (BMI) (weight in

\begin{tabular}{|c|c|}
\hline Food Groups & Food Items \\
\hline Processed meats & $\begin{array}{l}\text { Hot dog, sausage, hamburger, canned } \\
\text { tuna fish }\end{array}$ \\
\hline Meat and eggs & $\begin{array}{l}\text { Red meat (beef, lamb, veal), organ meats } \\
\text { (liver, heart, tongue), poultry (chicken } \\
\text { with or without skin, all preparations), } \\
\text { eggs (All preparations, including egg } \\
\text { salad and egg substitutes), fish, and } \\
\text { shellfish }\end{array}$ \\
\hline Dairy & $\begin{array}{l}\text { Milk, yogurt, curd, and cheese (except } \\
\text { cream cheese). }\end{array}$ \\
\hline Fruits and natural fruit juices & $\begin{array}{l}\text { Pears, apricots, cherries, sour cherry, } \\
\text { apples, grapes, bananas, cantaloupe, } \\
\text { melon, watermelon, oranges, grapefruit, } \\
\text { kiwi, strawberries, peaches, nectarine, } \\
\text { tangerine, mulberry, plums, persimmons, } \\
\text { pomegranates, lemons, pineapples, fresh } \\
\text { figs and natural fruit juices (oranges, } \\
\text { lime, other natural juices). }\end{array}$ \\
\hline Vegetables & $\begin{array}{l}\text { Green leafy (spinach, lettuce), yellow } \\
\text { vegetables, cruciferous vegetables } \\
\text { (cabbage, cauliflower, Brussels sprouts, } \\
\text { Cole slaw, broccoli, kale) and other } \\
\text { vegetables (cucumber, bell pepper, } \\
\text { mushroom, onion, peas, green beans, } \\
\text { sweet corn, eggplant, mushrooms, celery, } \\
\text { bean sprouts), Tomatoes, Turnip. }\end{array}$ \\
\hline Bread and grains & $\begin{array}{l}\text { Bread (local breads like barbari, sangak, } \\
\text { lavash and baguettes), rice, macaroni, } \\
\text { vermicelli, potatoes, corn/maize, oats, } \\
\text { grains, flour, and all types of noodle soup. }\end{array}$ \\
\hline Fats & $\begin{array}{l}\text { Non-hydrogenated vegetable oils (corn } \\
\text { oil, sunflower oil, canola oil and all other } \\
\text { vegetable oils), animal and hydrogenated } \\
\text { oils (animal and hydrogenated fats), } \\
\text { olives, olive oil, fried potatoes, } \\
\text { mayonnaise, butter, margarine, cream } \\
\text { cheese }\end{array}$ \\
\hline Legume and pulses & $\begin{array}{l}\text { Soybeans, lentils, beans, broad beans, } \\
\text { moong, peas, and split peas. }\end{array}$ \\
\hline Nuts and seeds & $\begin{array}{l}\text { Almonds, peanuts, walnuts, pistachios, } \\
\text { flaxseeds, other nuts, and seeds }\end{array}$ \\
\hline Sweets and dessert & $\begin{array}{l}\text { Chocolates, cookies, cakes, sugar (sugar } \\
\text { cube, refined sugar, honey), sweet } \\
\text { biscuits; crackers; drinks (soft drinks, } \\
\text { colas, industrial fruit juices), canned } \\
\text { fruits, dried fruits (dried raisins, figs, } \\
\text { dates, mulberries, apricots, and other } \\
\text { dried fruits) }\end{array}$ \\
\hline
\end{tabular}


$\mathrm{kg} /$ height in $\mathrm{m} 2$ ) was calculated on the basis of selfreported weights from maximum of 2 months before pregnancy, and height was measured in centimeters using a rod attached to the weighing scale at baseline.

The validity of the self-reported pre-pregnancy weight was documented, particularly if asked in early pregnancy $(35,36)$. The mother's BMI (weight in $\mathrm{kg} /$ height in $\mathrm{m}^{2}$ ) was then classified based on the definition of the Institute of Medicine (IOM) (37) and categorized to 4 groups as underweight $\left(<18.5 \mathrm{~kg} / \mathrm{m}^{2}\right)$, normal $(\geq 18.5$ and $<25$ $\mathrm{kg} / \mathrm{m}^{2}$ ), overweight ( $\geq 25$ and $<30 \mathrm{~kg} / \mathrm{m}^{2}$ ), and obese ( $\geq$ $\left.30 \mathrm{~kg} / \mathrm{m}^{2}\right)$.

To assess uniformity of the groups, the subjects were matched for age, pre-pregnancy weight, height, BMI, employment status, income, and educational background. Additional covariate information on age, pregnant female's educational level and job, husband's educational level, and family income, determined by analyzing the demographic information of the questionnaire.

\subsection{Statistical Analysis}

From the pilot study, the mean difference for the dairy intake of the questionnaire for groups A, B, and C was 1.25, 0.5 , and 0.2 respectively. Assuming a standard deviation of 1.3 for all groups, with $\alpha=0.05$ and $\beta=0.1$, the PASS 11.0 software resulted in a sample size of 38 subjects for each group. Assuming an attrition rate of $10 \%$, a total sample of 42 subjects was considered for each study group.

For the statistical analysis, quantitative and qualitative variables were reported, respectively, as mean (standard deviation) and frequency (percentage). The Analysis of Variance (ANOVA) test was used to compare the mean differences among the 3 groups wherein the distribution of the dependent variable was normal and the KruskalWallis test was utilized for non-normal variables. The post hoc comparisons were performed using the Tukey's and Mann-Whitney's tests. In addition, the Chi-square test was applied to compare the frequencies between groups using the Statistical Package for Social Sciences (SPSS21) software and P-values of $0<0.05$ were considered statistically significant.

\subsection{Ethical Considerations}

The ethics committee of Tarbiat Modares University approved the trial (IR.TMU.REC.1394.40), which was registered on www.Irct.IR(IRCT2016102530496N1).

\section{Results}

Initially, 150 eligible nulliparous pregnant females agreed to participate in the study. Fifty females were allocated to each of the groups, A, B, and the control group.
During the study, 22 participants were excluded due to discontinuing participation, miscarriage, and relocation (6 from the intervention group A, 7 from group B, and 9 from the control group). Figure 1 displays the flowchart of the study.

The mean age of the pregnant females was $25.93 \pm 3.7$ years (Table 2) and the mean pre-pregnancy weight, height, and BMI were $62.4 \pm 11.1 \mathrm{~kg}, 161.7 \pm 6.5 \mathrm{~cm}$, and $23.84 \pm 3.9$ $\mathrm{kg} / \mathrm{m}^{2}$, respectively (Table 3 ).

The one-way analysis of variance (ANOVA) and KruskalWallis tests showed that no statistically significant differences were observed between the intervention groups (A and $\mathrm{B}$ ) and the control group in terms of age, participant's and their husbands' educational level, working status, family income level (Table 2), and pre-pregnancy weight, height and BMI, according to the data collected at the beginning of the study (Table 3). Also no statistically significant differences were found between the servings of food group mean scores (including bread and grains, fruits and natural fruit juices, legume and pulses, sweets and dessert, nuts and seeds, meat and eggs, processed meats, dairy, fats, milk, yoghurt and vegetables) in the 3 groups before the intervention.

Within the interventions data, along with the control, there were no significant differences regarding the serving of food groups mean scores (Table 4).

According to self-reports, none of the pregnant females smoked or consumed alcohol during the first trimester (data not shown).

After the intervention, the mean difference of serving/day of vegetables was significantly higher in the intervention group A compared to group B and the control group $(\mathrm{P}<0.001$, Figure 2$)$. The mean differences of serving/day of dairy products (Figure 3 ) in group A and B were significantly higher than in the control group $(\mathrm{P}=0.001$ and $\mathrm{P}=0.005$, respectively) yet the mean difference of serving/day yoghurt from the dairy group in the intervention group A was significantly higher compared to group B and the control group $(P=0.024$, Figure 4$)$. Also, the mean differences of serving/day fats in the intervention groups ( $A$ and $B$ ) were significantly lower than in the control group $(\mathrm{P}=0.035)$. No significant difference was observed between the other food groups' intake (Figure 5 and Table 5).

\section{Discussion}

Maintaining proper nutrition and a healthy diet during pregnancy is critical for the well-being of the mother and growing fetus. Dietary educational counselling is a widely used strategic approach to improve the nutritional status of females during pregnancy (38).

In Iran, it was reported that there is a positive attitude towards spouses' participation in prenatal care and 


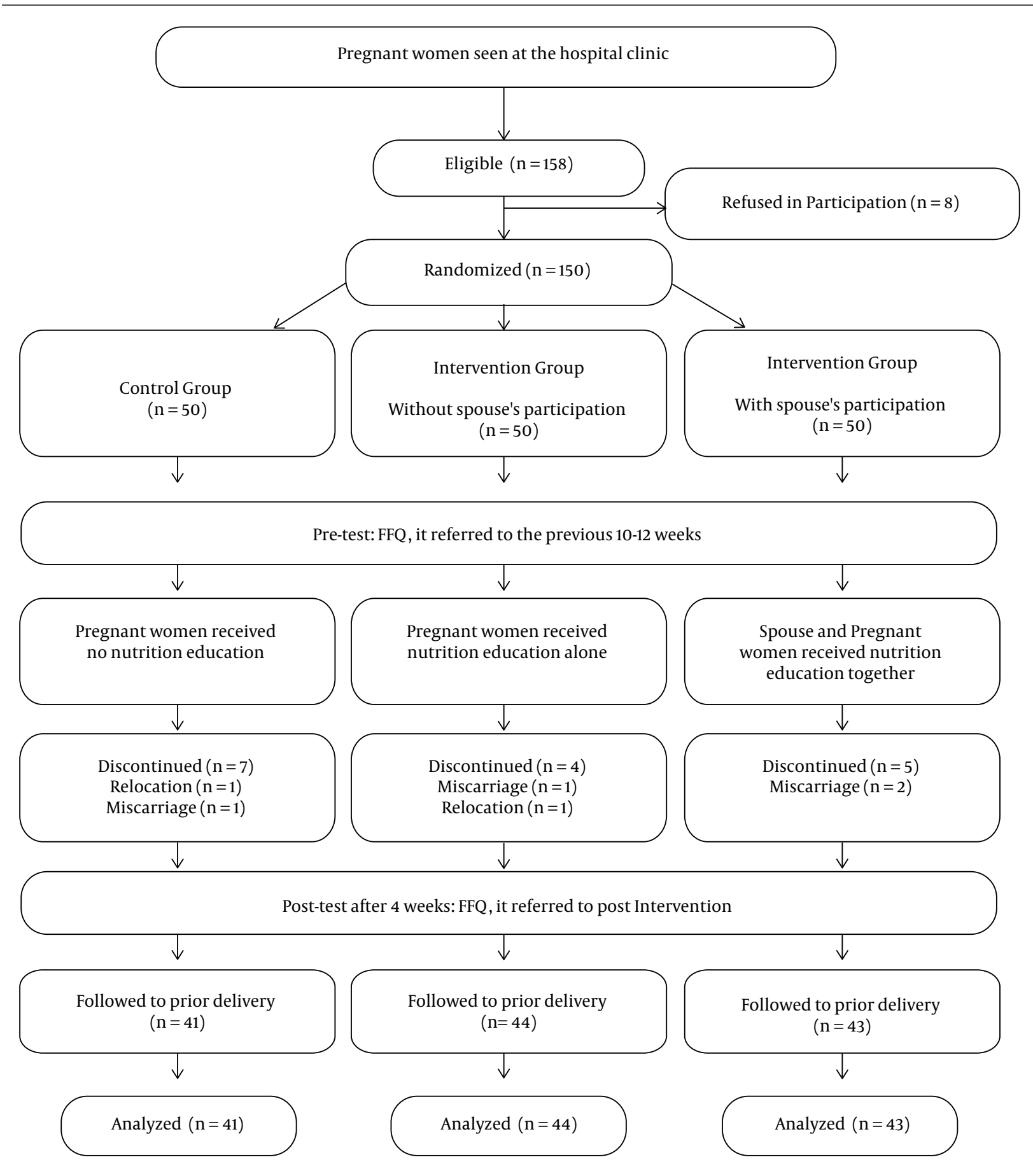

Figure 1. Flow Diagram of Participant Selection

believed that educational counselling is required for both pregnant mothers and their spouses. Most of participants preferred the face-to-face couples' counselling method. In addition, it was reported that males lacked adequate knowledge regarding helping their wives during pregnancy owing to their request for male's education (23).

Based on the above reports, this intervention study was conducted considering varied food groups with nu- 


\begin{tabular}{|c|c|c|c|c|}
\hline \multirow[t]{2}{*}{ Characteristics } & \multicolumn{3}{|c|}{ Groups } & \multirow[b]{2}{*}{ P Value } \\
\hline & $\operatorname{Group} A(n=43)$ & Group B $(n=44)$ & Group C $(n=41)$ & \\
\hline Pregnant women's age, y & & & & $0.754^{\mathrm{b}}$ \\
\hline$\leq 20$ & $2(4.7)$ & $4(9.1)$ & $1(2.6)$ & \\
\hline $21-30$ & $37(86.0)$ & $38(86.4)$ & $36(87.8)$ & \\
\hline $31-40$ & $4(9.3)$ & $2(4.5)$ & $4(9.8)$ & \\
\hline Mean \pm SD & $25.62 \pm 3.84$ & $25.52 \pm 3.22$ & $26.70 \pm 3.77$ & $0.280^{c}$ \\
\hline Pregnant women's educational level & & & & $0.305^{\mathrm{b}}$ \\
\hline High school diploma or diploma & $16(37.2)$ & $15(34.1)$ & $20(48.8)$ & \\
\hline University graduate & $23(53.5)$ & $27(61.4)$ & $18(43.9)$ & \\
\hline Post graduate & $4(9.3)$ & $2(4.5)$ & $3(7.3)$ & \\
\hline Husband's educational level & & & & $0.681^{\mathrm{b}}$ \\
\hline High school diploma or diploma & $17(39.5)$ & $19(43.2)$ & $18(43.9)$ & \\
\hline University graduate & $22(51.2)$ & $21(47.7)$ & $16(39.0)$ & \\
\hline Post graduate & $4(9.3)$ & $4(9.1)$ & $7(17.1)$ & \\
\hline Pregnant women's job & & & & $0.706^{\mathrm{b}}$ \\
\hline Unemployed & $31(72.1)$ & $33(75.0)$ & $28(68.3)$ & \\
\hline Employed & $12(27.9)$ & $11(25.0)$ & $13(31.7)$ & \\
\hline Family income & & & & $0.705^{\mathrm{b}}$ \\
\hline Low & $8(18.6)$ & $6(13.6)$ & $6(14.6)$ & \\
\hline Medium & $25(58.1)$ & $30(68.22)$ & $25(61.0)$ & \\
\hline High & $10(23.3)$ & $8(18.2)$ & $10(24.4)$ & \\
\hline Pre-pregnancy BMI, kg/m² & & & & $0.563^{\mathrm{b}}$ \\
\hline$\leq 18.5$ & $3(7.0)$ & $4(9.1)$ & $0(0.0)$ & \\
\hline $18.6-24.9$ & $26(60.5)$ & $30(68.2)$ & $27(65.9)$ & \\
\hline $25-29.9$ & $10(23.3)$ & $8(18.2)$ & $10(24.4)$ & \\
\hline$\geq 30$ & $4(9.3)$ & $2(4.5)$ & $4(9.8)$ & \\
\hline
\end{tabular}

${ }^{\mathrm{a}}$ Values are expressed as No. (\%) or mean \pm standard deviation (M \pm SD).

${ }^{\mathrm{b}}$ From Chi square test.

${ }^{\mathrm{c}}$ From ANOVA test.

\begin{tabular}{|c|c|c|c|c|c|}
\hline \multirow[t]{2}{*}{ Variable } & \multicolumn{3}{|c|}{ Groups } & \multirow[t]{2}{*}{ P Value } & \multirow[t]{2}{*}{ Total } \\
\hline & $\operatorname{Group} A(n=43)$ & Group B $(n=44)$ & Group C $(n=41)$ & & \\
\hline Height, cm & $161.53 \pm 6.03$ & $161.34 \pm 7.35$ & $162.17 \pm 6.3$ & $0.835^{\mathrm{b}}$ & $161.67 \pm 6.58$ \\
\hline Weight, kg & $62.34 \pm 11.45$ & $61.22 \pm 11.97$ & $64.68 \pm 10.27$ & $0.360^{\mathrm{b}}$ & $62.71 \pm 11.28$ \\
\hline BMI, $\mathrm{kg} / \mathrm{m}^{2}$ & $23.81 \pm 4.00$ & $23.19 \pm 4.01$ & $24.52 \pm 3.78$ & $0.303^{\mathrm{b}}$ & $23.83 \pm 3.94$ \\
\hline
\end{tabular}

${ }^{\mathrm{a}}$ Values are expressed as mean \pm standard deviation $(\mathrm{M} \pm \mathrm{SD})$.

${ }^{\mathrm{b}}$ From the ANOVA test.

tritional education counselling of pregnant females, and spouses' participation resulted in improvement of female's dietary health. However, in some food groups it resulted in additional improvement in pregnancy dietary intake of females owing to spouses' contribution as observed in Group A, wherein vegetable servings/day compared to intervention group B and control group was significant. 


\begin{tabular}{|c|c|c|c|c|}
\hline \multirow[b]{2}{*}{ Food Groups } & \multicolumn{3}{|c|}{ Serving Groups $(M \pm S D)$} & \multirow[t]{2}{*}{ P Value } \\
\hline & Group A & Group B & Group C & \\
\hline Processed meats/serving/day & $0.00(0.06) £$ & $0.01(0.07)$ & $0.00(0.06)$ & $0.946^{\mathrm{b}}$ \\
\hline Meat and eggs/serving/day & $0.99 \pm 0.58$ & $0.97 \pm 0.44$ & $0.84 \pm 0.31$ & $0.286^{c}$ \\
\hline Dairy/serving/day & $1.79 \pm 0.93$ & $2.00 \pm 1.18$ & $1.98 \pm 0.89$ & $0.597^{\mathrm{c}}$ \\
\hline Fruits and natural fruit juices/serving/day & $2.91 \pm 1.58$ & $3.72 \pm 1.97$ & $3.37 \pm 2.29$ & $0.165^{c}$ \\
\hline Vegetables/serving/day & $1.77 \pm 0.82$ & $2.07 \pm 0.85$ & $2.16 \pm 1.07$ & $0.128^{c}$ \\
\hline Bread and grains/serving/day & $6.91 \pm 2.70$ & $7.77 \pm 2.92$ & $7.07 \pm 2.14$ & $0.273^{c}$ \\
\hline Fats/serving/day & $7.63 \pm 4.30$ & $6.85 \pm 2.91$ & $7.71 \pm 3.80$ & $0.492^{c}$ \\
\hline Legumes and pulses/serving/day & $0.28(0.19)$ & $0.28(0.29)$ & $0.22(0.12)$ & $0.072^{\mathrm{b}}$ \\
\hline Nuts and seeds/serving/day & $0.82 \pm 0.71$ & $1.03 \pm 0.92$ & $0.85 \pm 0.80$ & $0.433^{c}$ \\
\hline Sweets and dessert/serving/day & $5.38 \pm 3.80$ & $5.97 \pm 4.19$ & $4.63 \pm 2.74$ & $0.240^{c}$ \\
\hline
\end{tabular}

${ }^{\mathrm{a}}$ Values are expressed as No. (\%) or mean \pm standard deviation (M \pm SD).

${ }^{\mathrm{b}}$ From Kruskal-Wallis test.

${ }^{\mathrm{c}}$ From ANOVA test.

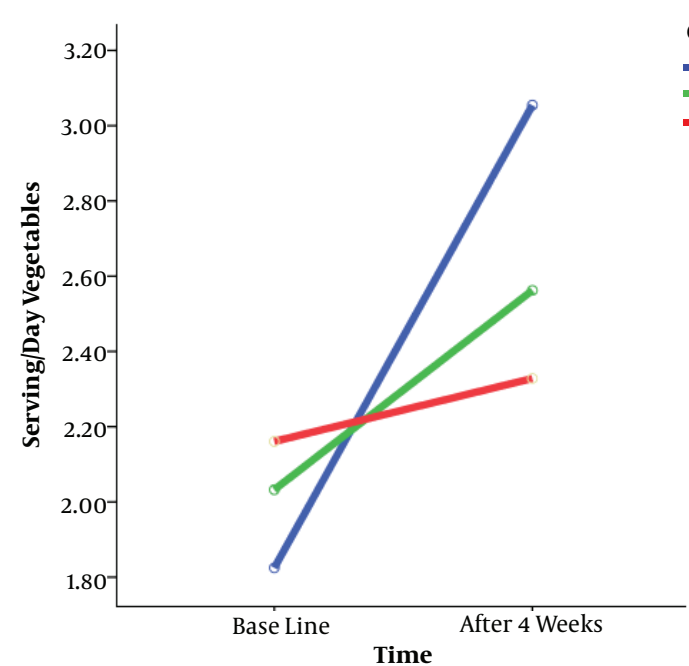

Figure 2. Changes of Serving/Day of Vegetables at the Base Line and 4 Weeks After Intervention in the Study Groups

Werbeck et al.'s study showed that female's dietary health was enhanced during pregnancy based on contribution of the physicians and family member's demands (39). Huhan stated that the family perception of implementing healthy dietary behavior could significantly contribute to pregnant female's nutrient intake from varied food groups (40). Similarly, Așcı and Rathfisch identified that lifestyle interventions among pregnant females were associated with improvements in vegetable intake (41).

It was observed that dietary intake of vegetables increased after an educational intervention, which con-



Figure 3. Changes of Serving/Day of Dairy Products at Base Line and 4 Weeks After the Intervention in the Study Groups

tributed as a key factor in the present study in relation to the difficulty of preparing vegetables, which was overcome by the spouses' participation. The family support of pregnant females in sustaining positive and healthy changes in the diet was documented previously (42).

Whitaker and Kara et al. reported that the majority of pregnant females viewed advice on dietary nutrition as a positive aspect, which motivated them to bring in change in their eating habits. For example, one participant said: "My eating habits were really unhealthy before they started telling me about it. Then I changed to eating better". Most 
Table 5. Food and Food Groups Serving Intake of Pregnant Women Before and After Nutritional Education

\begin{tabular}{|c|c|c|c|c|c|c|}
\hline Food and Food Groups & Group & $\mathbf{N}$ & Before Education & After Education & Differences $^{b}$ & PValue \\
\hline \multirow{3}{*}{ Processed meats/serving/day } & A & 43 & $0.00(0.06)$ & $0.00(0.05)$ & $0.00(-0.02)$ & \multirow{3}{*}{$0.371^{c}$} \\
\hline & B & 44 & $0.01(0.07)$ & $0.00(0.04)$ & $0.00(-0.04)$ & \\
\hline & C & 41 & $0.00(0.06)$ & $0.01(0.07)$ & $0.00(0.01)$ & \\
\hline \multirow{3}{*}{ Meat and Eggs/serving/day } & A & 43 & $0.99 \pm 0.58$ & $0.97 \pm 0.55$ & $0.02 \pm 0.58$ & \multirow{3}{*}{$0.978^{\mathrm{d}}$} \\
\hline & B & 44 & $0.97 \pm 0.44$ & $0.89 \pm 0.52$ & $-0.00 \pm 0.51$ & \\
\hline & $\mathrm{C}$ & 41 & $0.84 \pm 0.31$ & $0.82 \pm 0.48$ & $0.02 \pm 0.50$ & \\
\hline \multirow{3}{*}{ Dairy/serving/day } & A & 43 & $1.51 \pm 0.87$ & $3.49 \pm 1.42$ & $-1.97 \pm 1.43 a$ & \multirow{3}{*}{$0.001^{\mathrm{d}, \mathrm{e}}$} \\
\hline & B & 44 & $1.82 \pm 1.12$ & $3.48 \pm 1.28$ & $-1.66 \pm 1.54 b$ & \\
\hline & $\mathrm{C}$ & 41 & $1.94 \pm 0.73$ & $2.76 \pm 1.40$ & $0.81 \pm 1.34 \mathrm{~b}$ & \\
\hline \multirow{3}{*}{$\begin{array}{l}\text { Fruits and natural Fruit } \\
\text { juices/serving/day }\end{array}$} & A & 43 & $2.91 \pm 1.58$ & $3.28 \pm 2.34$ & $0.05 \pm 1.77$ & \multirow{3}{*}{$0.377^{\mathrm{d}}$} \\
\hline & B & 44 & $3.72 \pm 1.97$ & $3.10 \pm 1.59$ & $0.62 \pm 2.27$ & \\
\hline & $\mathrm{C}$ & 41 & $3.37 \pm 2.29$ & $2.86 \pm 1.40$ & $0.08 \pm 2.29$ & \\
\hline \multirow{3}{*}{ Vegetables/serving/day } & A & 43 & $1.77 \pm 0.82$ & $3.04 \pm 1.60$ & $-1.27 \pm 1.52 \mathrm{a}^{\mathrm{e}}$ & \multirow{3}{*}{$<0.001^{\mathrm{d}}$} \\
\hline & $\mathrm{B}$ & 44 & $2.07 \pm 0.85$ & $2.49 \pm 0.97$ & $-0.41 \pm 0.87 b$ & \\
\hline & C & 41 & $2.16 \pm 1.07$ & $2.37 \pm 1.26$ & $-0.21 \pm 1.35 b$ & \\
\hline \multirow{3}{*}{ Bread and grains/serving/day } & A & 43 & $6.91 \pm 2.70$ & $6.75 \pm 3.31$ & $0.15 \pm 3.80$ & \multirow{3}{*}{$0.852^{\mathrm{d}}$} \\
\hline & B & 44 & $7.77 \pm 2.92$ & $7.77 \pm 3.64$ & $-0.01 \pm 3.75$ & \\
\hline & $\mathrm{C}$ & 41 & $7.07 \pm 2.14$ & $7.36 \pm 2.66$ & $-0.28 \pm 3.14$ & \\
\hline \multirow{3}{*}{ Fats/serving/day } & A & 43 & $7.63 \pm 4.30$ & $5.04 \pm 2.19$ & $2.58 \pm 4.09 \mathrm{a}^{\mathrm{e}}$ & \multirow{3}{*}{$0.028^{\mathrm{d}}$} \\
\hline & B & 44 & $6.85 \pm 2.91$ & $5.66 \pm 2.74$ & $1.18 \pm 3.31 \mathrm{a}$ & \\
\hline & C & 41 & $7.71 \pm 3.80$ & $7.32 \pm 4.10$ & $0.38 \pm 3.84 \mathrm{~b}$ & \\
\hline \multirow{3}{*}{ Legume and pulses/serving/day } & A & 43 & $0.36 \pm 0.36$ & $0.39 \pm 0.37$ & $-0.03 \pm 0.46$ & \multirow{3}{*}{$0.521^{\mathrm{d}}$} \\
\hline & B & 44 & $0.38 \pm 0.26$ & $0.35 \pm 0.21$ & $0.02 \pm 0.31$ & \\
\hline & C & 41 & $0.25 \pm 0.17$ & $0.33 \pm 0.33$ & $-0.08 \pm 0.36$ & \\
\hline \multirow{3}{*}{ Nuts and Seeds/serving/day } & A & 43 & $0.82 \pm 0.71$ & $0.69 \pm 0.53$ & $0.12 \pm 0.77$ & \multirow{3}{*}{$0.505^{\mathrm{d}}$} \\
\hline & B & 44 & $1.03 \pm 0.92$ & $0.80 \pm 0.50$ & $0.22 \pm 1.06$ & \\
\hline & C & 41 & $0.85 \pm 0.80$ & $0.86 \pm 0.84$ & $-0.01 \pm 0.93$ & \\
\hline \multirow{3}{*}{ Sweets and dessert/serving/day } & A & 43 & $5.38 \pm 3.80$ & $4.26 \pm 3.03$ & $1.11 \pm 3.90$ & \multirow{3}{*}{$0.432^{\mathrm{d}}$} \\
\hline & B & 44 & $5.97 \pm 4.19$ & $4.98 \pm 3.12$ & $0.99 \pm 3.81$ & \\
\hline & C & 41 & $4.63 \pm 2.74$ & $4.41 \pm 2.66$ & $0.21 \pm 2.24$ & \\
\hline \multirow{3}{*}{ Milk } & A & 43 & $0.58 \pm 0.64$ & $1.39 \pm 0.85$ & $-0.80 \pm 0.89$ & \multirow{3}{*}{$0.005^{\mathrm{d}}$} \\
\hline & B & 44 & $0.75 \pm 0.75$ & $1.50 \pm 0.81$ & $-0.75 \pm 1.11$ & \\
\hline & $\mathrm{C}$ & 41 & $0.74 \pm 0.55$ & $0.94 \pm 0.65$ & $-0.19 \pm 0.70$ & \\
\hline \multirow{3}{*}{ Yogurt } & A & 43 & $0.35(0.28)$ & $1.00(0.50)$ & $-0.50(0.60) \mathrm{a}^{\mathrm{f}}$ & \multirow{3}{*}{$0.024^{\mathrm{c}}$} \\
\hline & B & 44 & $0.44(0.44)$ & $0.71(0.50)$ & $-0.37(1.01) \mathrm{b}$ & \\
\hline & C & 41 & $0.50(0.59)$ & $0.50(0.92)$ & $-0.10(0.58) b$ & \\
\hline
\end{tabular}

${ }^{\mathrm{a}}$ Values are expressed as No. (\%) or mean \pm standard deviation $(\mathrm{M} \pm \mathrm{SD}$ ).

${ }^{\mathrm{b}}$ Differences: were calculated as: Baseline scores minus after intervention scores.

${ }^{\mathrm{c}}$ From Kruskal-Wallis test.

${ }^{\mathrm{d}}$ From ANOVA test.

${ }^{\mathrm{e}}$ Identical small letters show non-significant difference based on Tukey test.

${ }^{\mathrm{f}}$ Mann-Whitney's test. 


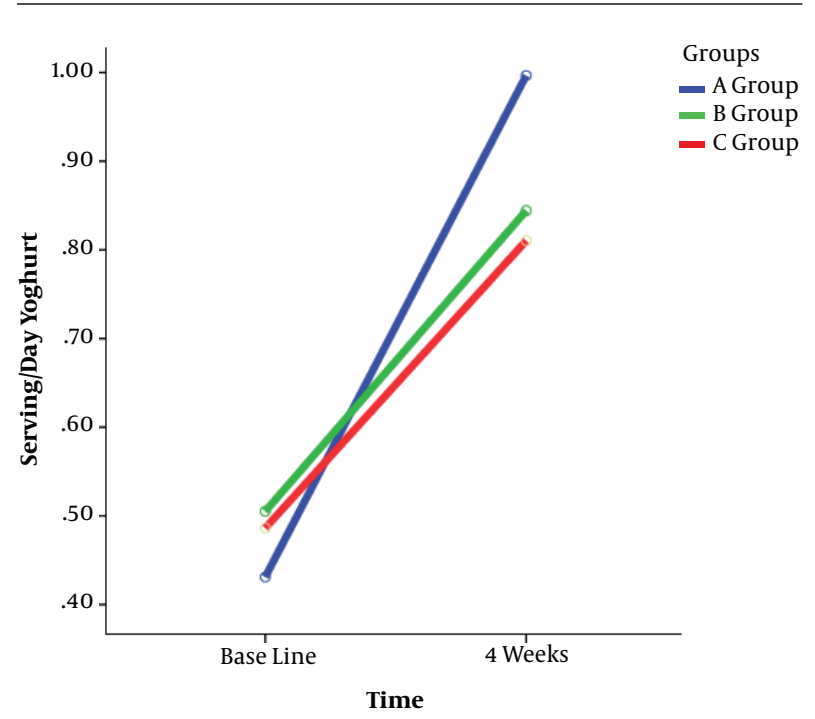

Figure 4. Changes of Serving/Day of Yoghurt at the Base Line and 4 Weeks After the Intervention in the Study Groups

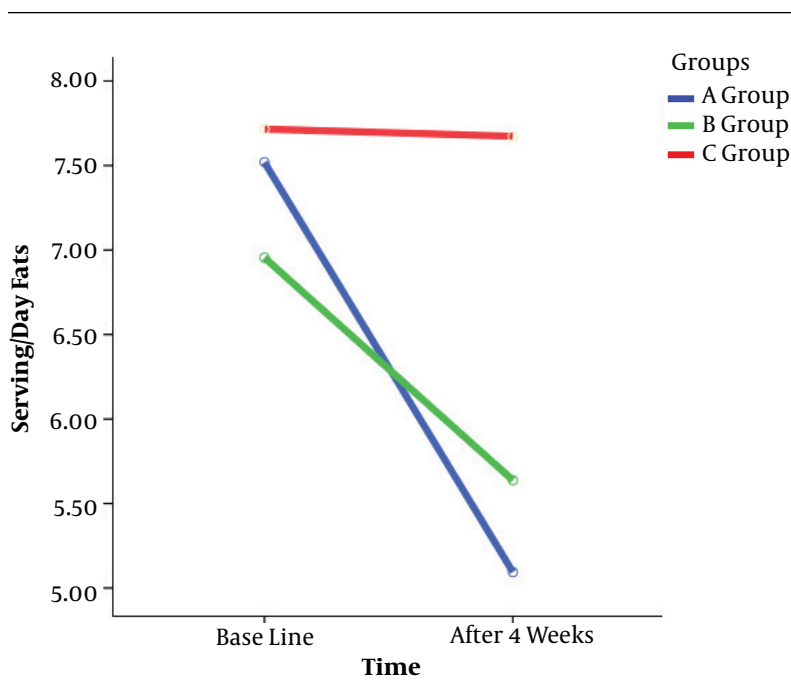

Figure 5. Changes of Serving/Day of Fats at the Base Line and 4 Weeks After the Intervention in the Study Groups

of the females reported on eating more fruits and vegetables and less unhealthy food items owing to positive diet counselling (43).

In addition, the present study found that the mean differences of servings/day of dairy in groups A and B was significantly higher than the control group. Although group A showed higher values than group B for servings/day of dairy, their mean score showed no significance.

Pertaining to a dairy source, another noted aspect was the mean difference of serving/day of yoghurt, which was significantly higher in intervention group A compared to
B and the control group. In all attributes, spouses' participation played a vital role.

These results suggest that dietary pattern improved regarding the mean scores of vegetables, milk and dairy products, which include protein source and several key vitamins and minerals.

Various studies have reported that nutritional counselling among pregnant females was associated with improvements in dietary intake. Fallah et al. and Kafatos et al. found that education on nutrition and food consumption could cause a positive change to improve levels of the nutritional knowledge of pregnant females $(44,45)$.

Paramjit et al. found that nutritional education on the pregnant female's dietary intake could cause an increase in levels of milk and milk products and vegetables consumption. However, a more detailed approach is required to improve pregnancy diet wherein suggested participation of spouses could help eliminate certain eating habit drawbacks, such as vegetables, milk, and yoghurt compared to the control group (46).

In the current study, consumption of fruits before and after the intervention showed no significant mean score among the 3 groups.

Observations pertaining to fruit consumption before the intervention among the pregnant females in all 3 groups showed \pm 3 servings/day whereas after 4 weeks of intervention all participants in group A and B obtained \pm 4 servings/day of fruits and in the control group participants reported \pm 4.5 servings/day. However, no remarkable alteration in mean score among the 3 groups was examined.

Therefore, it could be suggested that pregnant females had gained sufficient knowledge regarding nutritional intake from fruits consumption as stated by Așcı and Rathfisch, where the intervention groups and control group had similar outcomes to that of the current study (41).

However, the study conducted by Tanha et al. during pregnancy could help remarkably increase the mean score of fruits and vegetables intake (42).

The results also showed a significant decrease in the mean difference of servings/day of fats in the intervention groups and a reduction was higher with the spouses' participation. Similarity with the current study, pertaining to the intervention of fat consumption, was observed by Hui et al. (47).

Although improvement of dietary food group intake is important and was considered in the present study, some of the dietary groups like legumes and pulses, meat and eggs, bread and brains along with sweets and dessert serving/day had no significance.

It has been reported that the majority of females did not have enough knowledge on the influence of dietary nourishment before pregnancy on the development of the fetus. However, this had no relevance to their eating habits 
(48). Additionally, Dos Santo, et al. in their study reported that despite increasing coverage and access to prenatal care in Brazil, inadequate nutrient intake was frequent in females during pregnancy because they did not alter their food intake (49). Although all females considered it important to increase nutrient intake during pregnancy, only a quarter of them in southern Ethiopia reported to do so as observed by Asayehu et al. (50)

In another study on 40108 pregnant females, it was reported that they did not commonly change the types of foods they consumed and rather changed the relative amounts (51).

Furthermore, Stotland et al. in their study titled "Preventing excessive weight gain in pregnancy: how do prenatal care providers approach counselling?" mentioned insufficient skills of education providers as another important aspect, where improvement in their teaching ability was suggested to assure the effectiveness of their education. As a result, the education providers reported on their desire to learn new techniques for counselling pregnant females about weight gain and nutrition. They also identified several barriers to weight gain counselling, including insufficient training, concerns about the sensitivity of the topic, and the perception that counselling is ineffective. The providers all agreed that weight gain was an important topic with short-term and long-term health consequences, yet they described widely disparate counselling styles and approaches. The physicians also believed their medical school and residency training in prenatal nutrition and weight gain counselling was inadequate. The participants used personal experiences and emphasized on press materials to educate themselves and their patients (52).

Considering the mentioned barriers to behavioral change and the effectiveness of education in choosing a better life style, this study identified that spouses' participation on educational intervention might lead to improvement in the diet of females during pregnancy.

It is interesting to note that Otieno et al. reported, after an intervention for the spouses' participation on deciding about food choice, husbands giving their wives authority in decision making on food choice was 3 times more than the control group (53).

Therefore, spouses' participation either encouraged them to talk about healthy food choices with their family or leave the decision making to their wives or resulted in health dietary plans for the family. Stimulating discussions on how to purchase healthy foods could be a big educational performance.

\subsection{Strengths and Limitations of the Study}

In order to develop a structured data pattern, the research team decided to have 3 study groups comprised of
2 comparative and 1 control group. In addition, applying "Telegram/Line" as an accessible messaging service might have strengthened the affects.

A probable limitation could be generalizing the results only to pregnant females attending antenatal clinics. Furthermore, the self-report data gathering method of this study may have caused over, and/or underestimation of food intake. Reporting on eaten food during at least the previous 2 months on memory basis may have involved forgetting some aspects.

\subsection{Conclusions}

Nutritional education intervention, especially with spouses' participation, could increase proper nutrient intake among pregnant females in comparison with those, who received routine prenatal care, yet no advice on dietary intake.

Future studies pertaining to educational interventions should be considered as an effective nutritional approach to improve male's participation in dietary health programs as part of prenatal care.

\section{Acknowledgments}

The authors would like to thank the authorities of Tarbiat Modares University of Medical Sciences for the scientific and ethical approval and financial support of this research. We also sincerely thank authorities of Najmieh hospital in Tehran, all the personnel of the health care, and particularly all the mothers and spouses, who participated in this study. The authors are thankful to the authorities of Tarbiat Modares University (TMU) for the ethics and scientific approval and financial support.

\section{Footnotes}

Authors' Contribution: Kiani Asiabar and Farkhondeh Amin Shokravi set up the study. Kiani Asiabar, Farkhondeh Amin Shokravi, and Majid Hajifaraji was responsible for intervention and data collection. Kiani Asiabar, Farkhondeh Amin Shokravi, and Farid Zayeri performed the analyses and Interpretation of data. Kiani Asiabar, Farkhondeh Amin Shokravi, Majid Hajifaraji, and Farid Zayeri drafted the article. All authors contributed to the interpretation of the results and took part in revising the article.

Clinical Trial Registration Code: The study was registered on www.Irct.IR(IRCT2016102530496N1).

Conflict of Interests: Authors have no direct financial interests that might pose a conflict of interest in connection with the submitted manuscript. 
Ethical Approval: The ethics committee of Tarbiat Modares University approved the trial (IR.TMU.REC.1394.40).

Funding/Support: The Tarbiat Modares University provided funding for this study.

Informed Consent: A written consent form was obtained from the participants.

\section{References}

1. Mora JO, Nestel PS. Improving prenatal nutrition in developing countries: strategies, prospects, and challenges-. Am J Clin Nutr. 2000;71(5):1353S-63S.

2. Chen X, Zhao D, Mao X, Xia Y, Baker PN, Zhang H. Maternal Dietary Patterns and Pregnancy Outcome. Nutrients. 2016;8(6). doi: 10.3390/nu8060351. [PubMed: 27338455].

3. Yargawa J, Leonardi-Bee J. Male involvement and maternal health outcomes: systematic review and meta-analysis. J Epidemiol Community Health. 2015;69(6):604-12. doi: 10.1136/jech-2014-204784. [PubMed: 25700533].

4. Lewis S, Lee A, Simkhada P. The role of husbands in maternal health and safe childbirth in rural Nepal: a qualitative study. BMC Pregnancy Childbirth. 2015;15:162. doi: 10.1186/s12884-015-0599-8. [PubMed: 26239123].

5. Mullany BC, Becker S, Hindin MJ. The impact of including husbands in antenatal health education services on maternal health practices in urban Nepal: results from a randomized controlled trial. Health Educ Res. 2007;22(2):166-76. doi: 10.1093/her/cyl060. [PubMed: 16855015].

6. Vermeulen E, Solnes Miltenburg A, Barras J, Maselle N, van Elteren $\mathrm{M}$, van Roosmalen J. Opportunities for male involvement during pregnancy in Magu district, rural Tanzania. BMC Pregnancy Childbirth 2016;16:66. doi: 10.1186/s12884-016-0853-8. [PubMed: 27021593].

7. Troesch B, Biesalski HK, Bos R, Buskens E, Calder PC, Saris WH, et al. Increased Intake of Foods with High Nutrient Density Can Help to Break the Intergenerational Cycle of Malnutrition and Obesity. Nutrients. 2015;7(7):6016-37. doi: 10.3390/nu7075266. [PubMed: 26197337].

8. Schoenaker DA, Soedamah-Muthu SS, Mishra GD. The association between dietary factors and gestational hypertension and preeclampsia: a systematic review and meta-analysis of observational studies. BMC Med. 2014;12:157. doi: 10.1186/s12916-014-0157-7. [PubMed: 25241701].

9. Tryggvadottir EA, Medek H, Birgisdottir BE, Geirsson RT, Gunnarsdottir I. Association between healthy maternal dietary pattern and risk for gestational diabetes mellitus. EurJClin Nutr. 2016;70(2):237-42. doi: 10.1038/ejcn.2015.145. [PubMed: 26350393].

10. Chen LW, Aris IM, Bernard JY, Tint MT, Colega M, Gluckman PD, et al. Associations of maternal macronutrient intake during pregnancy with infant BMI peak characteristics and childhood BMI. Am J Clin Nutr 2017;105(3):705-13. doi: 10.3945/ajcn.116.148270. [PubMed: 28179222].

11. Starling AP, Sauder KA, Kaar JL, Shapiro AL, Siega-Riz AM, Dabelea D. Maternal Dietary Patterns during Pregnancy Are Associated with Newborn Body Composition. J Nutr. 2017;147(7):1334-9. doi: 10.3945/jn.117.248948. [PubMed: 28539412].

12. Shim JS, Oh K, Kim HC. Dietary assessment methods in epidemiologic studies. Epidemiol Health. 2014;36. e2014009. doi: 10.4178/epih/e2014009. [PubMed: 25078382].

13. Kominiarek MA, Rajan P. Nutrition Recommendations in Pregnancy and Lactation. Med Clin North Am. 2016;100(6):1199-215. doi: 10.1016/j.mcna.2016.06.004. [PubMed: 27745590].

14. Montazerifar F, Karajibani M, Sotoudeh M, Amrollahi B. Evaluation of nutritional status in pregnant women in iranshahr, Iran. Med Surg Nurs J. 2014:3(2):98-1.

15. Adikari AMNT, Sivakanesan R, Wijesinghe DGNG, Liyanage C. Assessment of nutritional status of pregnant women in a rural area in Sri Lanka. Trop Agric Res. 2016;27(2):203. doi: 10.4038/tar.v27i2.8168.
16. Azami M, Darvishi Z, Sayehmiri K. Systematic review and metaanalysis of the prevalence of anemia among pregnant Iranian women (2005-2015). Shiraz E Med J. 2016;17(4-5).

17. Rahbar N, Ghorbani R, Rezaei Ahvanoei F. Prevalence of iron deficiency anemia and its complications in pregnant women referred to medical-health centers in Semnan. Iran J Obstetr Gynecol Infertil. 2014;17(128):12-7.

18. Mohammadi M, Baghaei H, Movahed A, Akbarzadeh S, Kowsarifard M, Hajivandi A. Serum level of Zinc and Copper among pregnant women of Jam area referred to Towhid Hospital, southern part of Bushehr. ISMJ. 2015;18(2):344-52.

19. Olang B, Abdollahi Z, Neshati R, Ali MA, Naghavi M, Yngve A. Vitamin A status in pregnant women in Iran in 2001 and its relationship with province and gestational age. Food Nutr Res. 2014;58. doi: 10.3402/fnr.v58.25707. [PubMed: 25317119].

20. Abbasian M, Chaman R, Amiri M, Ajami ME, Jafari-Koshki T, Rohani H, et al. Vitamin D Deficiency in Pregnant Women and Their Neonates. GlobJHealth Sci.2016;8(9):54008. doi:10.5539/gjhs.v8n9p83. [PubMed: 27157170].

21. Bhatta DN. Involvement of males in antenatal care, birth preparedness, exclusive breast feeding and immunizations for children in Kathmandu, Nepal. BMC Pregnancy Childbirth. 2013;13:14. doi: 10.1186/1471-2393-13-14. [PubMed: 23324410].

22. August F, Pembe AB, Mpembeni R, Axemo P, Darj E. Community health workers can improve male involvement in maternal health: evidence from rural Tanzania. Glob Health Action. 2016;9:30064. doi: 10.3402/gha.v9.30064. [PubMed: 26790461].

23. Simbar M, Nahidi F, Ramezani-Tehrani F, Akbarzadeh A. Educational needs assessment for men's participation in perinatal care. East Mediterr Health J. 2011;17(9):689-96. [PubMed: 22259920].

24. Davis J, Vyankandondera J, Luchters S, Simon D, Holmes W. Male involvement in reproductive, maternal and child health: a qualitative study of policymaker and practitioner perspectives in the Pacific. Reprod Health. 2016;13(81).

25. Chakrabarti S, Sarkar D. Awareness and involvement of male spouse in various aspects of antenatal care: observation in a rural area of West Bengal. Int J Commun Med Public Health. 2017;4(4):1179-82.

26. Odimegwu C, Adewuyi A, Odebiyi T, Aina B, Adesina Y, Olatubara O, et al. Men's role in emergency obstetric care in Osun State of Nigeria. Afr J Reprod Health. 2005;9(3):59-71. [PubMed: 16623190].

27. Ahmed F, Tseng M. Diet and nutritional status during pregnancy. Public Health Nutr. 2013;16(8):1337-9. doi: 10.1017/S1368980013001651. [PubMed: 23830246].

28. Dunneram Y, Jeewon R. Healthy Diet and Nutrition Education Program among Women of Reproductive Age: A Necessity of Multilevel Strategies or Community Responsibility. Health Promot Perspect. 2015;5(2):116-27. doi: 10.15171/hpp.2015.014. [PubMed: 26290827].

29. Nair MK, Augustine LF, Konapur A. Food-Based Interventions to Modify Diet Quality and Diversity to Address Multiple Micronutrient Deficiency. Front Public Health. 2015;3:277. doi: 10.3389/fpubh.2015.00277. [PubMed: 26779472].

30. Grieger JA, Clifton VL. A review of the impact of dietary intakes in human pregnancy on infant birthweight. Nutrients. 2014;7(1):153-78. doi: 10.3390/nu7010153. [PubMed: 25551251].

31. Abdullahi Z, Dorosti MR, Fallah H, Bakhshandeh M, Torabi P, Rahmani K. Comprehensive guide for nutrition during pregnancy for the Ministry of Health and Medical Education of Iran. Qum, Iran; 2014.

32. Mirmiran P, Esfahani FH, Mehrabi Y, Hedayati M, Azizi F. Reliability and relative validity of an FFQ for nutrients in the Tehran lipid and glucose study. Public Health Nutr. 2010;13(5):654-62. doi: 10.1017/S1368980009991698. [PubMed: 19807937].

33. Esmaillzadeh A, Kimiagar M, Mehrabi Y, Azadbakht L, Hu FB, Willett WC. Dietary Patterns and Markers of Systemic Inflammation among Iranian Women. J Nutr. 2007;137(4):992-8. doi: 10.1093/jn/137.4.992.

34. Center for Nutrition Policy and Promotion. The food guide pyramid. 2015. 
35. Yu SM, Nagey DA. Validity of self-reported pregravid weight. Ann Epidemiol.1992;2(5):715-21. doi:10.1016/1047-2797(92)90016-j.

36. Stevens-Simon C, Roghmann KJ, McAnarney ER. Relationship of selfreported prepregnant weight and weight gain during pregnancy to maternal body habitus and age. J Am Diet Assoc. 1992;92(1):85-7. [PubMed: 1728630].

37. Institute of Medicine. Weight Gain During Pregnancy: Reexamining the Guidelines.2009. Available from: http://www.nationalacademies.org/ hmd/ /media/Files/Report\%20Files/2009/Weight-Gain-DuringPregnancy-Reexamining-the-Guidelines/Report\%20Brief\%20$\% 20$ Weight $\% 20$ Gain $\% 20$ During\%20Pregnancy.pdf.

38. Word Health Organization. Nutrition counselling during pregnancy. 2017. Available from: http://www.who.int/elena/titles/nutrition counselling_pregnancy/en/.

39. Verbeke W, De Bourdeaudhuij I. Dietary behaviour of pregnant versus non-pregnant women. Appetite. 2007;48(1):78-86. doi: 10.1016/j.appet.2006.07.078. [PubMed: 17005297].

40. Lin YH, Tsai EM, Chan TF, Chou FH, Lin YL. Health promoting lifestyles and related factors in pregnant women. Chang Gung Med J. 2009;32(6):650-61. [PubMed: 20035645].

41. Asci O, Rathfisch G. Effect of lifestyle interventions of pregnant women on their dietary habits, lifestyle behaviors, and weight gain: a randomized controlled trial. J Health Popul Nutr. 2016;35:7. doi: 10.1186/s41043-016-0044-2. [PubMed: 26911204].

42. Tanha FD, Mohseni M, Ghajarzadeh M, Shariat M. The effects of healthy diet in pregnancy.J Fam Reproductive Health. 2013;7(3):121.

43. Whitaker KM, Wilcox S, Liu J, Blair SN, Pate RR. Patient and Provider Perceptions of Weight Gain, Physical Activity, and Nutrition Counseling during Pregnancy: A Qualitative Study. Womens Health Issues. 2016;26(1):116-22. doi: 10.1016/j.whi.2015.10.007. [PubMed: 26621605].

44. Fallah F, Pourabbas A, Delpisheh A, Veisani Y, Shadnoush M. Effects of Nutrition Education on Levels of Nutritional Awareness of Pregnant Women in Western Iran. Int J Endocrinol Metabol. 2013;11(3). doi: 10.5812/ijem.9122

45. Kafatos AG, Vlachonikolis IG, Codrington CA. Nutrition during pregnancy: the effects of an educational intervention program in Greece. Am J Clin Nutr. 1989;50(5):970-9. [PubMed: 2816804].

46. Chawla K, Puri R; Paramjit. Impact of nutrition education on food and nutrient intake of pregnant women. Indian J Matern Child Health. 1996;7(1):11-5. [PubMed: 12320377].

47. Hui A, Back L, Ludwig S, Gardiner P, Sevenhuysen G, Dean H, et al Lifestyle intervention on diet and exercise reduced excessive gestational weight gain in pregnant women under a randomised controlled trial. BJOG. 2012;119(1):70-7. doi: 10.1111/j.1471-0528.2011.03184.x. [PubMed: 22017967].

48. Kozlowska-Wojciechowska M, Wujec MM. [Dietary knowledge and practice in pregnant women]. Rocz Panstw Zakl Hig. 2002;53(2):167-75. [PubMed: 12235673].

49. dos Santos Q, Sichieri R, Marchioni DM, Verly Junior E. Brazilian pregnant and lactating women do not change their food intake to meet nutritional goals. BMC Pregnancy Childbirth. 2014;14:186. doi 10.1186/1471-2393-14-186. [PubMed: 24890188].

50. Asayehu TT, Lachat C, Henauw S, Gebreyesus SH. Dietary behaviour, food and nutrient intake of women do not change during pregnancy in Southern Ethiopia. Matern Child Nutr. 2017;13(2). doi 10.1111/mcn.12343. [PubMed: 27373896].

51. Hure A, Young A, Smith R, Collins C. Diet and pregnancy status in Australian women. Public Health Nutr. 2009;12(6):853-61. doi 10.1017/S1368980008003212. [PubMed: 18647425].

52. Stotland NE, Gilbert P, Bogetz A, Harper CC, Abrams B, Gerbert B. Preventing excessive weight gain in pregnancy: how do prenatal care providers approach counseling? J Womens Health (Larchmt). 2010;19(4):807-14. doi: 10.1089/jwh.2009.1462. [PubMed: 20078239].

53. Otieno P, Farnworth C, Banda N. Involving Men in Nutrition. GFRAS; 2016. Available from: www.betterextension.org. 